\title{
THE REPORTS ON THE PROGRESS OF PHARMACY.
}

C. L. DIEHL, REPORTER ON THE PROGRESS OF PHARMACY.

This is not intended to be an introductory to the Report on the Progress of Pharmacy, but a concise statement of the status of the Reports for 1912 and 1913 , the one past due, the other to become due within a reasonable time after the middle of January of next year; incidentally also of causes that have led up to delay in the publication of the Report for 1911 and their influence upon the delay in publishing the one for 1912 and the possible tardiness in finishing the manuscript for that of 1913.

It will be remembered that at the meeting in Boston, 1911, it was decided to change the fiscal year of the Association so as to cover the full number of months of the calendar year-from January to December, inclusive. It was also decided that the Report on the Progress of Pharmacy should hereafter cover the entire calendar year instead of, as heretofore, from July of one year to June 30 of the next, and with this object in view, the Reporter was directed to include the abstracts covering the six months of 1911, from July 1 to December 31 , in his report for that year. This meant, of course, six additional months' work, and a report covering a period of eighteen months instead of twelve months for 1911. It meant also a loss of approximately three months' time to do this work of six; hence the completion of the report would necessarily be further delayed to that extent beyond the time which had been previously conceded for the systematic arrangement, unavoidable delays, etc., which consumed usually from July to October.

Nevertheless, and notwithstanding some unavoidable delays (due to other important work for the Association), the report, properly arranged for the printer, was forwarded by express to the General Secretary on June 5, 1912, and had the manuscript gone immediately into the hands of the printer, the report might have been delivered to the members within at most three months thereafter.

As a matter of fact, by action of the Council, the publication was delayed so that the printer did not get to work on the report until late in September; at all events, the first installment of galley proofs was received by me for correction September 23, 1912, and the last installment on May 5, 1913-fifty-eight installments of galley proofs of text and perhaps five or six of index page proofs being received in all, and in each case corrected and returned on the same day or by the next mail during that period. And on June 21, forty-seven days thereafter, I received the bound volume.

I do not know how to account for the extraordinary delay, but am inclined to think that it was due to a combination of fortuitous conditions for which no one in particular is to blame. It is clear to my mind, however, that under normal conditions, it is quite possible to get out the report within three months after the complete text has reached the printer's hands. So far as the index is concerned, this goes hand in hand with the correction of the page proofs, and there was no delay on this score except the scarcity of type-the index being unexpectedly voluminous. 
Now, regarding the Report for 1912. The manuscript for this has been ready since the end of February of this year, but has remained in my hands because of the indecision as to the manner of its publication, resulting from my plea addressed to the Council against the method adopted at Denver. The members who have read the Council Letters in the Journal of the Association are doubtless familiar with my views, as well as with the views of others who differ with me and of those who support my views, and I have no argument to make now other than to say that I would consider it exceedingly unfortunate if the decision at this meeting should be in favor of the Denver proposition.

If, however, the Association shall recind its action at Denver, and decide that the report shall be issued as a separate publication, like the Report of 1911, the manuscript can be systematically arranged shortly after adjournment of the present meeting, and ready for the printer by the middle of September at the latest. If then the galley proofs reach me daily and regularly, the printing should not require more than sixty days and the binding could follow quickly, so that by February 1st the volume could be distributed to the members.

Owing to illness during the early part of this year, coupled with work on the N. F. and on the U.S. P. demanding much of my attention, the preparation of abstracts for the Report of 1913 has not progressed as favorably as I could wish. Yet, with the assistance of my collaborators I can reasonably hope to have the manuscript ready for the printer by the middle of March or early in April, and the report should then be ready for distribution on or before July 1 , 1914.

Finally, it is my opinion that under normal conditions, free from the handicap of National Formulary and Pharmacopœia work, it will be quite possible to get out the volume by May 1st of each year, particularly if the collaborators will give the same assistance-for which my thanks are due them-in future reports as they have in the one for 1912, and have promised for the Report of 1913.

\section{REPORT OF THE COMMITTEE ON LOCAL BRANCHES.}

THEO. D. WETTERSTROEM, CHAIRMAN.

The Committee on Organization of Local Branches of the A. Ph. A. reports that a branch has been organized in Cincinnati, Ohio, during the past year. On February 11, 1913, the initial meeting was held at the Lloyd Library and a full list of officers was elected.

Meetings are held second Tuesday of each month.

The meetings have been very interesting and well attended. A largely increased membership is expected this coming winter.

Professor C. T. P. Fennel was elected member of Council to represent the Cincinnati Section.

Respectfully submitted,

Theo. D. Wetterstroem, Cincinnati, O.

George B. Kauffman, Columbus, O.

D. V. Whitney, Kansas City, Mo.

F. R. ElDRED, Indianapolis, Ind.

Charles W. Johnson, Seattle, Wash. 